\title{
Mediation service in special closed-type educational institutions (SCTEI)
}

\author{
Valeria Aleksandrovna Terentyeva ${ }^{1}$ and Irina Anatolievna Gaag \\ Kemerovo State University, Department of Criminal Law and Criminology, Kemerovo, Russia
}

\begin{abstract}
The purpose of the research is to study the influence of the mediation service on the correction of SCTEI trainees, highlight their main differences with the psychological and pedagogical service, and conduct a comparative analysis of similar services abroad. Such fundamental methods of scientific knowledge as general methods (analysis, synthesis, induction, deduction, analogy), as well as special methods (comparative legal and formal legal), provided the methodological basis for this research. The work used the published data from the Pathways to Desistance studies; in relation to 1,354 juvenile offenders. The data from a survey of 100 minors held in SCTEI of the Siberian Federal District were used. The research results concluded that the creation at SCTEI of mediation services engaged in constructive conflict resolution and ensuring effective achievement of mutual understanding between the parties to the conflict determine the humanity of education, the priority of human life and health, the rights and freedoms of an individual. It was also found by the authors that it had had a positive effect on the creation of a culture of safe and trusting communication between students, their parents and the teaching staff of the institution, on the prevention of violent, aggressive approaches in interpersonal interaction, the prevention of manifestations of antisocial behaviour, professional and emotional burnout of employees. In addition, it was found that with the functioning of the mediation service, students at SCTEI would also get an idea of how to become a part of society. The novelty of the research is due to the author's approach to the problem under study as well as the fact that during the research it was found that it is mediation that makes it possible to create a dual system model of self-control for students at SCTEI.
\end{abstract}

Keywords: child welfare, family law, right to education

\section{Introduction}

The mediation services at SCTEI in relation to teenagers in conflict with the law raise many questions. For example, concerning the relationship between the powers of a mediator and a teacher-psychologist, as well as the need for legislative regulation of mediation assistance to the family, to which the adolescent will return. Also, the issue of the connection between the mediation service and the socio-psychological service SCTEI has not been resolved; the possibility of parents' involvement in the mediation procedure as a conflicting party has not

\footnotetext{
${ }^{1}$ Corresponding author: terent@list.ru
} 
been enshrined. The mediation (or mediator-worker) service is especially relevant in SCTEI, as are the mediation methods for resolving conflicts that arise in a closed society, where the parties are forced to constantly contact each other.

Age characteristics and peculiarities of the legal status of adolescents in conflict with the law require the legislator to search for new ways of protecting and realising the rights of minors. Adverse childhood experiences, especially abusive treatment, are considered significant antisocial behaviour risk factors during adolescence [1]. A teenager, who has committed a crime, is perceived by law not only as a subject of criminal law but also as a subject of increased protection which leads to the need to expand the tools for the implementation of his/her rights and interests. This problem is especially acute in SCTEI which implement one of the types of exemption from criminal punishment.

Reconstruction of the SCTEI system, which began with the adoption of the federal law dated 29 December 2012 No. 273-FZ "Education in the Russian Federation" and was further developed with the adoption of the Order of the Ministry of Education of the Russian Federation dated 17 July 2019 No. 381 "Approval of the Procedure for Organising and Implementing Activities Special Educational Institutions of Open and Closed Types", significantly changed the area of the activities of those institutions. SCTEI should now ensure the humanistic nature of education, the priority of human life and health, the rights and freedoms of an individual, the free development of an individual. To a greater extent, this corresponds to the creation at SCTEI of mediation services engaged in constructive resolution of conflicts and ensuring the achievement of mutual understanding between the parties to the conflict.

Mediation, as an element of civil society, is functionally linked to fundamental universal human values, such as human rights, the rule of law and democracy; it is an instrument for their protection by people themselves in the form of joint resolution of interpersonal conflicts by virtue of professional mediators. The use of mediation is not just a settlement tool but an educational process that supports the creation and promotion of social norms. Mediation should be understood as a form of self-regulation based on the ideas of honesty, fairness and trust [2].

\section{$2 \quad$ Methods}

The methodological basis of this research was such fundamental methods of scientific knowledge as general methods (analysis, synthesis, induction, deduction and analogy) as well as special methods (comparative legal and formal legal). This work used the published data from Pathways to Desistance studies; in relation to 1,354 juvenile offenders. We also used data from a survey of 100 minors held in SCTEI of the Siberian Federal District.

\section{$3 \quad$ Results}

The materials studied show:

The development of the mediation system in SCTEI is provided for by the Order of the Russian Federation Government dated 30 July 2014 No. 1430-r, which approved the "Concept for the development of a network of mediation services until 2017 in order to implement restorative justice in relation to children, including those who have committed socially dangerous acts, but not have reached the age at which criminal liability arises in the Russian Federation". According to this instrument, mediation-restorative methods and mechanisms for preventing and resolving conflicts with the participation of children and 
adolescents should be applied, also in relation to children who have committed socially dangerous acts.

In Kuzbass, a mediation service has been created and has been successfully operating at the Kaltanskoye SCTEI Federal State Budgetary Educational Institution. In this institution, in 2017, a socially significant event was held to develop a model for the "Family Conference" restorative justice programme [3]. Specialists from the Russian Restorative Mediation Association took part in the project. On 10 August 2019, an action focused on maintaining and strengthening mental health was held at the Kaltansky SCTEI was held. The participants took part in watching motivational videos, self-diagnosis classes, performed relaxation exercises with aromatherapy and listened to psychological poetry.

Measures for the creation and support of mediation services at SCTEI (including the aforementioned parent conference) are being implemented within the framework of the State Assignment by the Federal Mediation Institute. This experience shows that due to the integration of mediation and restorative technologies and the operation of the mediation service at SCTEI, the relationship between the students improved, and there were no serious conflict situations. Also, the relationships in the SCTEI team, as well as between employees and students have improved, which improves the authority of educators and teachers.

\section{Discussion}

At SCTEI, for students with deviant behaviour, a mediation service is created to protect the rights and interests of children, help them in difficult situations, and better socialise adolescents (Section III of the Concept). To achieve these goals, mediators use a "restorative approach", which is included in multisystem therapy [4], which provides for a rehabilitation programme at the social level, educational and vocational training, restoration of relationships, trust through compensation for material and moral damage... This approach uses the skills and abilities of adolescents.

When applying a restorative approach to mediation, the social rehabilitation should be combined with academic and professional training [5-8]. In addition, in the literature it is noted that the effectiveness of mediation with this approach depends on the individual work; family education and employment; and use of the right medicines [9]. As the studies have shown, this is fully implemented in SCTEI, since elements of two types of mediation are used here because adolescents in those institutions are not only in conflict with each other but also in conflict with the society. Firstly, it is traditional mediation, and secondly, it is narrative mediation. Mediation of the first type is mainly used to resolve interpersonal conflicts, while mediation of the second type is mainly used to resolve conflicts between human communities [10].

The Concept states that the main criterion for the effective implementation of the mediation method should be to ensure that the mediation service network for all those in need of assistance and protection is available. To ensure this, it is possible to create a similar service (or mediator worker) in each SCTEI, where conflict resolution mediation methods are especially relevant, since they arise in a closed society, where the parties are forced to contact each other very often. The social control theory and its role in the moderate mediation model also point to the relationship between perceived institutional microclimate and delinquency. Research in this area shows with confidence that enhanced control mitigates both direct and indirect links between microclimate and juvenile delinquency [11]. In addition, the constantly emerging conflicts destabilise the situation in the institution, which often leads to the commission of new offenses by minors. 
In the territory of the Russian Federation in the Siberian Federal District, in the structure of various SCTEIs, there are two options for ensuring that media technologies are used. The analysis shows that the creation of the mediation service at SCTEI is based on its capabilities and needs. It can be either part of a socio-psychological or other service, or it can be an independent unit.

If the mediation service is an independent unit, then it includes the staff of the institution who have undergone professional retraining, and very often the administration of the institution invites representatives of other mediation services. If a mediation service is created with the involvement of external specialists, the SCTEI administration gets to know the principles of mediation and restorative practice and, together with them, determines an action plan for integrating mediation and restorative practices into SCTEI's activities. This format allows you to see the problem at the initial level of development and make efforts to solve it from different angles, which makes it possible to prevent the escalation of a negative situation. When creating a mediation service as an independent unit, the issue of financing is very important; employees need to be trained, their qualifications maintained, wages paid, new premises are needed for the service. This is why many SCTEIs hire a third-party mediator to work with minors.

If mediation is carried out by the psychological and pedagogical service, it is necessary to distinguish between the powers and requirements for mediators and educational psychologists.

Mediators and educational psychologists have different educational requirements. Thus, a teacher-psychologist should have a field-specific higher professional education or secondary vocational education [12]. There is no such requirement for mediators, they just need to undergo advanced training of approximately 72-576 hours, which makes it possible to master both the skills of restorative practice and mediation [13].

According to the Concept and Methodological Guidelines, a mediator is an independent neutral intermediary between the conflicting parties, whose task is to find a way out of the current situation that is beneficial to both parties to the conflict. A mediator equalises the parties in negotiations, supports them in finding a solution. Unlike a mediator, an educational psychologist should study the reasons that led to the conflict, the emotions and feelings of the conflicting people, whether the parties have intrapersonal problems. Based on this information, he/she chooses strategies to improve the psychological well-being of the individual which is often not related to conflict resolution. The educational psychologist often conducts individual work with the victim of the conflict. Mediation techniques can be used in the work of a psychologist, for example, in the treatment of gambling and cyber addiction; with mediation techniques, the issue of the inadmissibility of transferring cyber violence into real life is resolved [14].

Mediation applies to all involved parties to a conflict. We believe that parents should also be such. However, it remains unclear whether it is possible for the parents of a minor to participate in the mediation procedure in SCTEI as one of the parties to a conflict. It is believed that such participation is necessary, as it will improve the family situation, and, consequently, reduce the criminality of the environment where the teenager returns. Indeed, often the conflict behaviour of children is caused precisely by the unfavourable psychoemotional situation in the family (for example, the parents' divorce) [15, p. 11].

\section{Conclusion}

By evaluating the SCTEI experience in the implementation of mediation techniques for resolving conflicts, the following conclusions can be drawn. The creation of mediation 
services at SCTEI has a positive effect on shaping a culture of safe and trusting communication between students, their parents, the teaching staff of the institution, as well as preventing violent and aggressive approaches in interpersonal interaction, preventing manifestations of antisocial behaviour, professional and emotional burnout of employees. It is mediation that helps in the creation of a dual systemic model of self-control. General levels of self-control are established during childhood and remain largely unchanged [16]. SCTEI students also develop an understanding of how to become a part of society. It is believed that for a more effective functioning of mediation services in SCTEI, a more detailed settlement of the issue of the relationship between the mediation service and the socio-psychological service is necessary, as well as legitimisation of the parents' participation in the mediation procedure as a conflicting party.

\section{References}

1. Protic S, Wittmann L, Taubner S, Dimitrijevic A. Differences in attachment dimensions and reflective functioning between traumatized juvenile offenders and maltreated non-delinquent adolescents from care services. Child Abuse Negl. 2020 May;103:104420. doi: 10.1016/j.chiabu.2020.104420. Epub 2020 Mar 5. PMID: 32146268.

2. L. Allport, Amicus Curiae, 2, 151-168 (2021). https://doi: 10.14296/ac.v2i2.5251

3. Belonogova E., Sviridova I. A Regional Model to Train Mediators for the Educational System of Kuzbass Journal of Siberian Federal University. Humanities \& Social Sciences 2020 13(9): 1449-1465 DOI: 10.17516/1997-1370-0655

4. M. Azam, A. Bakar, M. Yusoff, A. Rauf, Children and Youth Services Review, 122, 105911 (2021). https://doi.org/10.1016/j.childyouth.2020.105911

5. M.T. Baglivio, K.T. Wolff, A.R. Piquero, M. DeLisi, M.G. Vaughn, Justice Quarterly, 35(3), 443-476 (2018). https://doi.org/10.1080/07418825.2017.1317013

6. E.P. Baumer, K. Cundiff, L. Luo, Criminology, 59(1) (2020). https://doi.org/10.1111/1745-9125.12264

7. R. Bucci, J. Staff, Criminology, 58(3), 537-567 (2020). https://doi.org/10.1111/1745-9125.12245

8. Case S., Hazel N. Child first, offender second - A progressive model for education in custody//International Journal of Educational Development Volume 77, September 2020// https://www.sciencedirect.com/science/article/pii/S073805932030403X

9. K. Sint, R. Rosenheck, Haiqun Lin, Statistics in Medicine, 40(12), 2800-2820 (2021). https://doi.org/10.1002/sim.8929

10. P. Patsurkivskyy, R. Havrylyuk, I. Yuriichuk, European Journal of Law and Public Administration, 7(2), 137-150 (2021). https://doi.org/10.18662/eljpa/7.2/134

11. J. Zhang, D. Li, N. Ahemaitijiang, W. Peng, B. Zhai, Y. Wang, Children and Youth Services Review, 116, 105253 (2020).

https://doi.org/10.1016/j.childyouth.2020.105253

12. Order of the Ministry of Health and Social Development of the Russian Federation dated 26 August 2010 No. 761n (as amended on 31 May 2011) "Approval of the Unified Qualification Reference Book of Positions of Managers, Specialists and Employees, Section "Qualification Characteristics of the Positions of Educational Workers”, Rossiyskaya Gazeta, 237 (2010) 
13. The concept of development until 2017 of a mediation service network in order to implement restorative justice in relation to children including those who have committed socially dangerous acts but have not reached the age at which criminal responsibility occurs in the Russian Federation approved by the order of the Russian Federation Government dated 30 July 2014, No. 1430-r. Accessed on: July 5, 2021. [Online]. Available: http://www.pravo.gov.ru

14. Y. Cho, S. DioGuardi, Children and Youth Services Review, 108, 104601 (2020). https://doi.org/10.1016/j.childyouth.2019.104601

15. M.V. Bykova, A.A. Vinokurov, V.P. Grafsky, A.Kh. Pacheco Reinaga, A.A. Pentin, Guidelines for the creation of mediation services and the integration of a restorative approach in special educational institutions for children and adolescents of an open type or closed type (FSBI "FIM", Moscow, 2019)

16. T. Wojciechowski, Journal of Criminal Justice, 70, 101716 (2020).

https://doi.org/10.1016/j.jcrimjus.2020.101716 